\title{
Myocardial Infarction or Takotsubo Cardiomyopathy? A Case Report of a Rare Clinical Dilemma in the Setting of Atrial Myxoma
}

\author{
Balasubramaniyan AmirthaGanesh ${ }^{1}$ Sasinthar Rangasamy ${ }^{2}$, Arumugam Aashish \\ Selvaraj Karthikeyan ${ }^{1,0 .}$ \\ ${ }^{1}$ Department of Cardiology, Mahatma Gandhi Medical College and
Research Institute, Pondicherry, India
2Department of Cardiology, Vadamalayan Hospitals, Madurai, Tamil
Nadu, India62119122 \\ Ind J Car Dis Wom 2021;6:119-122.

\begin{abstract}
Address for correspondence Sasinthar Rangasamy MD, DM, Vadamalayan Hospitals, Madurai, Tamil Nadu 625002, India
\end{abstract} \\ (e-mail: sasinthar87@gmail.com).
}

\begin{abstract}
Keywords

- Takotsubo cardiomyopathy

- myocardial infarction

- atrial myxoma

- embolization

- case report

Background Acute myocardial infarction (AMI) secondary to coronary embolization is one of the rare complications of atrial myxoma. Takotsubo cardiomyopathy (TCM), a close mimic of AMI, is extremely rare in the setting of atrial myxoma. We report a patient with atrial myxoma presenting with features leading to a clinical dilemma between these two entities.

Case summary A 60-year-old woman presented with acute chest pain with ST segment elevation. Echocardiogram revealed left ventricular (LV) apical ballooning which is typical of TCM, coexisting with a fragile left atrial mass. Emergency coronary angiogram showed a hazy lesion in the circumflex ostium and an intermediate lesion in ramus without any obstruction. Surgical excision of the tumor was done due to features of recurrent coronary embolism. The histopathology examination confirmed it as a myxoma. Regional wall motion abnormalities reversed within a month and LV function normalized. Cardiac magnetic resonance (CMR) imaging at follow-up suggested myocardial infarction.

Discussion TCM can occur very rarely in the setting of atrial myxoma. In a patient with atrial myxoma presenting with features of TCM, differentiating it from coronary embolization is important.
\end{abstract}

\section{Introduction}

Cardiac myxomas are benign tumors typically manifesting as embolic, obstructive, or constitutional symptoms. Coronary embolization due to atrial myxoma is uncommon with an incidence of $0.06 \%{ }^{1}$ Takotsubo cardiomyopathy (TCM) is acute-onset reversible cardiomyopathy typically precipitated by acute emotional or physical stress. TCM in the setting of atrial myxoma is rarely reported. ${ }^{2,3,4,5}$ Differentiating between AMI and TCM in the presence of coronary artery disease becomes challenging. ${ }^{6}$

We describe a patient with acute coronary syndrome after a stressful event in the family, associated with incidentally detected left atrial myxoma, leading to a diagnostic dilemma between TCM and AMI secondary to coronary embolization.
DOI https://doi.org/ $10.1055 / \mathrm{s}-0041-1734397$
(C) 2020. Women in Cardiology and Related Sciences.

This is an open access article published by Thieme under the terms of the Creative Commons Attribution-NonDerivative-NonCommercial-License, permitting copying and reproduction so long as the original work is given appropriate credit. Contents may not be used for commercial purposes, or adapted, remixed, transformed or built upon. (https://creativecommons.org/licenses/by-nc-nd/4.0/).

Thieme Medical and Scientific Publishers Pvt. Ltd. A-12, 2nd Floor, Sector 2, Noida-201301 UP, India 


\section{Case Presentation}

A 60-year-old woman, suffering from hypertension and diabetes,, presented with compressive chest pain for 12 hours. She had progressive dyspnea of New York Heart Association (NYHA) class II to class III over 4 years, with paroxysmal nocturnal dyspnea (PND) for 3 months. A month ago, her husband had died. On examination, there was a loud first heart sound and an intermittent low-pitched early diastolic sound followed by a mid-diastolic rumble.

Electrocardiogram (ECG) showed ST elevation in inferolateral leads (-Fig. 1). Peak troponin I was175 ng/L. Other routine investigations were insignificant.

A bedside two-dimensional (2D) transthoracic echocardiogram (TTE) (-Fig. 2) showed regional wall motion

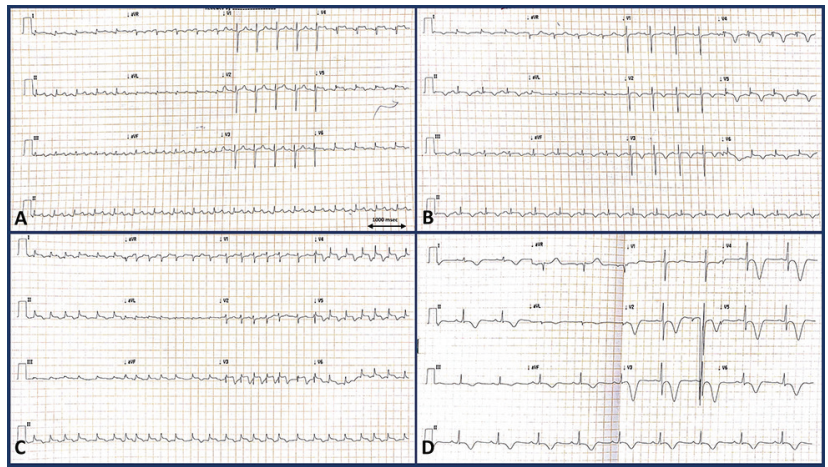

Fig. 1 [MC8]Electrocardiogram of the patient at different timelines. (a) (At presentation, day 1 ) Sinus tachycardia at $100 \mathrm{bpm}$ with ST segment elevations in leads V4-V6, I, aVL, II, III, and aVF with biphasic T wave inversions and ST segment depression in lead aVR. (b) (Day 2) Sinus rhythm at $90 \mathrm{bpm}$ with new onset deep T inversions in leads V2-V6, I, avL, II, III, and avF with minimal ST elevations in leads V4-V6, I, aVL. (c) (Postoperative) Atrial fibrillation with fast ventricular rate with persistent ST elevations in V3-V6, I, aVL, II, III, and aVF. (d) Follow-up ECG 1 month later showing sinus rhythm at $60 \mathrm{bpm}$, no pathological Q waves, symmetrical deep T inversions in V2-V6, II, III, avL, and I with QTc interval prolongation.

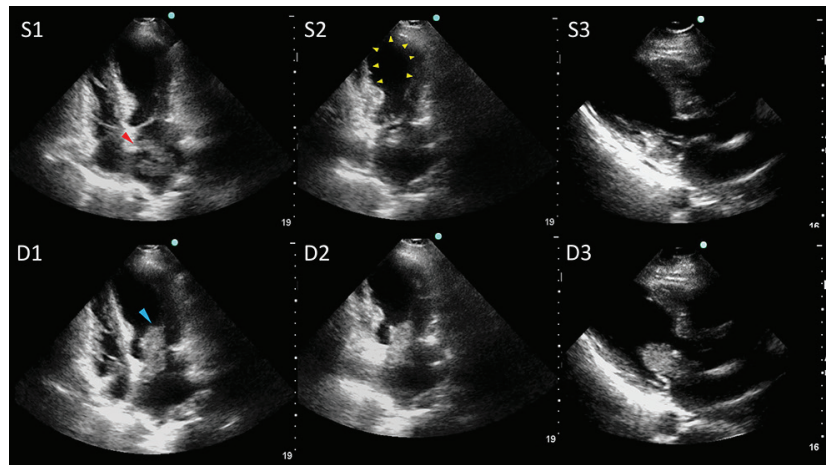

Fig. 2 Transthoracic echocardiogram still frame images at presentation. Upper panels (S1, S2, and S3): Systolic frames in apical four-chamber, apical two-chamber, and parasternal long axis views showing regional wall motion abnormalities causing LV apical ballooning (yellow arrowheads) with hyperkinetic LV base. Note the friable pedunculated mass in the left atrium with attachment to the interatrial septum (red arrowhead). Lower panels (D1, D2, and D3): Diastolic frames in apical four-chamber, apical two-chamber, and parasternal long axis views showing the mass prolapsing into the LV obstructing the mitral inflow (blue arrowhead).

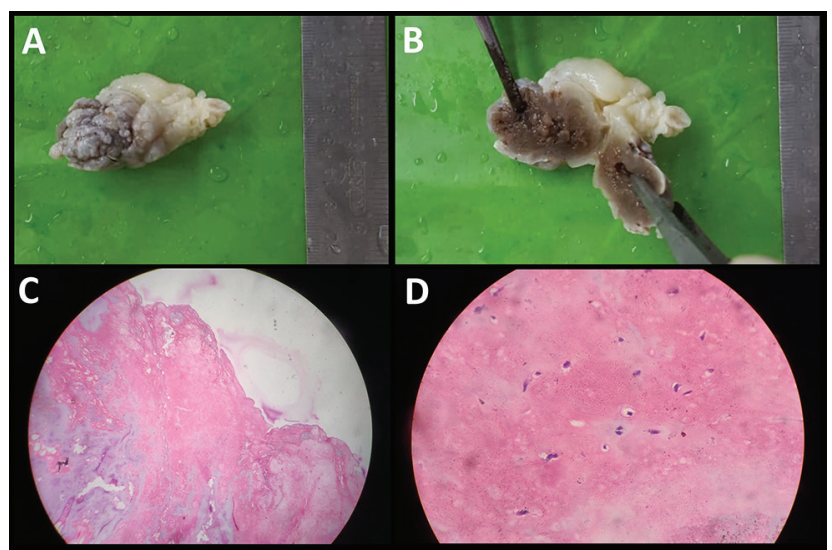

Fig. 3 (a,b) Gross pathology of the left atrial myxoma showing yellowish, irregular, soft, friable mass. (c,d) Histopathology showing spindle-shaped cells embedded in abundant extracellular matrix consistent with benign atrial myxoma. (H\&E, hematoxylin and eosin; panel c: $40 \times$ and panel d 100× magnification).

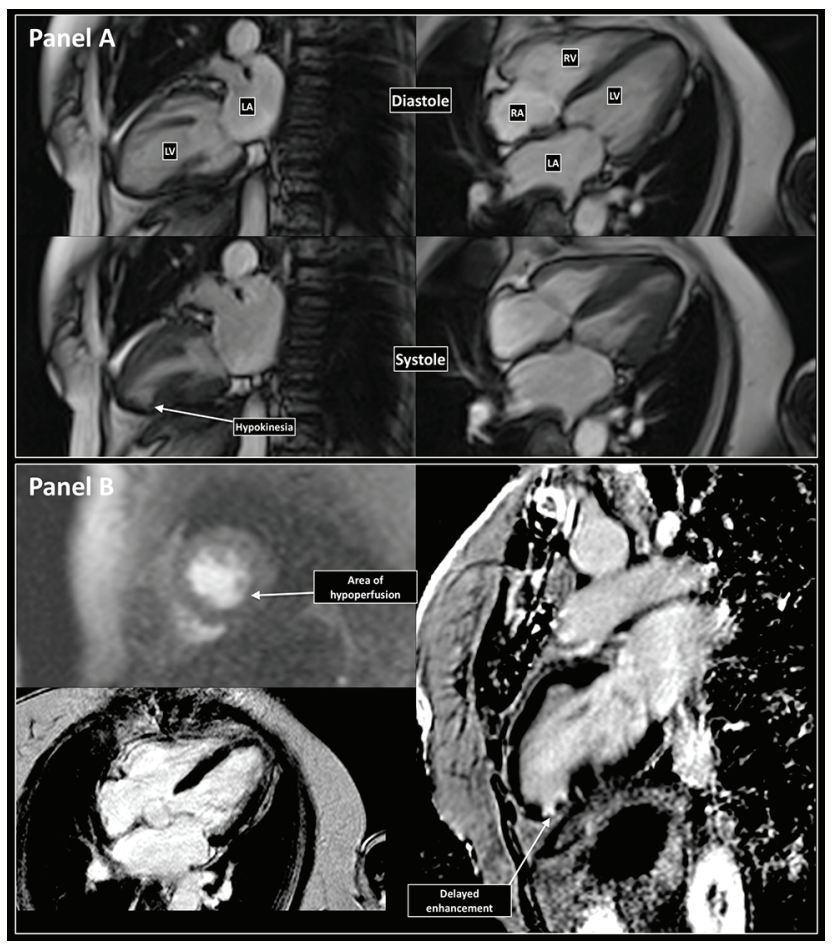

Fig. 4 Cardiac magnetic resonance imaging at 3 months follow-up. (a) Diastolic (top row) and systolic (bottom row) frames of true FISP "bright blood" images of the heart showing failure of systolic thickening of apical inferior wall suggestive of regional wall motion abnormality. (b) Top left: Dynamic gadolinium enhanced myocardial perfusion imaging showing a small area of impaired perfusion at the hypokinetic region. Bottom left: 4-chamber T2-weighted spin echo image shows no evidence of myocardial edema. Right: Delayed images obtained shows bright subendocardial LGE involving apical inferior and inferolateral wall suggestive of scar.

abnormality (RWMA) causing left ventricular (LV) systolic apical ballooning typical of TCM (Supplementary Videos 1-3). Left ventricular ejection fraction (LVEF) was $38 \%$. There was a large polypoid friable left atrial mass of size $51 \mathrm{~mm} \times 28 \mathrm{~mm}$, attached to the fossa ovalis. 
An emergency coronary angiogram (CAG) revealed nonobstructive coronaries and TIMI III flow. She was put on conservative management following which chest pain improved.

The next day she developed recurrent chest pain associated with fresh $\mathrm{T}$ wave inversion in the anterior leads. Suspecting recurrent embolic showers, she was taken up for emergency surgical excision of atrial myxoma. A soft friable mass of $\sim 40 \mathrm{~mm} \times 30 \mathrm{~mm}$ was excised in toto. Patient's clinical condition improved, and she was extubated. A TTE done before discharge showed significant improvement of RWMA with an LVEF of $45 \%$. The histopathological examination of the resected tumor confirmed the diagnosis of atrial myxoma (-Fig. 3).

At 1-month follow-up, LV function normalized and no RWMA was detectable by echocardiogram. A cardiac magnetic resonance (CMR) imaging done at 3 months ( - Fig. 4) showed normal LVEF (65\%), RWMA of inferior and inferolateral wall of the LV apex, and a small area of impaired perfusion with late gadolinium enhancement (LGE), suggesting that the past event was not only stress cardiomyopathy but there was also a vascular event. The patient was free of dyspnea or angina on further follow-up.

\section{Video 1}

Two-dimensional transthoracic echocardiogram in parasternal long axis view showing LV apical ballooning and the myxoma. Online content including videos available at https://doi.org/10.1055/s-0041-1734397.

\section{Video 2}

Two-dimensional transthoracic echocardiogram in apical four-chamber view showing LV apical ballooning and the myxoma attached to interatrial septum by a stalk. Online content including videos available at https://doi. org/10.1055/s-0041-1734397.

\section{Video 3}

Two-dimensional transthoracic echocardiogram in apical two-chamber view showing LV apical ballooning and the myxoma. Online content including videos available at https://doi.org/10.1055/s-0041-1734397.

\section{Discussion}

Atrial myxoma presenting with embolization is regarded as a "surgical emergency" because risk of recurrent embolization increases with time. ${ }^{7}$
TCM usually occurs in postmenopausal women typically following physical or emotional stress. Death of a loved one and exacerbation of a chronic medical condition (atrial myxoma) might be the potential triggers in our patient. TCM can mimic AMI and is characterized by LV systolic apical ballooning. ${ }^{8}$ There are only few cases of TCM reported in the setting of LA myxoma. ${ }^{2,3,4,5,9}$

Differentiating TCM from AMI based on history, clinical examination, ECG, and cardiac enzymes can be difficult. ${ }^{10}$ The troponin-ejection fraction product (TEFP) is 665 (peak troponin I $17.5 \mathrm{ng} / \mathrm{dL} \times$ LVEF $38 \%$ ) which is slightly high and also CK-Mb was slightly higher too, favoring AMI. ${ }^{11}$ Whereas the InterTAK diagnostic score is 74 (-Table $\mathbf{1}$ ), indicating a high probability of TCM. ${ }^{12} \mathrm{LV}$ apical ballooning in TTE can also be seen in occlusion of a wraparound LAD or when showers of myocardial embolization involves multiple coronary artery territories. ${ }^{13} \mathrm{NT}$ PRO BNP levels were marginally elevated and it could be explained by failure secondary to LV dysfunction which occur in both AMI and TCM. CAD can coexist in 15\% cases of TCM. ${ }^{8}$ So both the modified Mayo Clinic diagnostic criteria and the InterTAK diagnostic criteria for TCM allow the presence of concurrent CAD. ${ }^{4,15}$

Also, TCM and acute STEMI can rarely occur concurrently. ${ }^{16}$ CMR is increasingly recognized as a modality of choice to differentiate TCM from AMI in doubtful cases. TCM usually does not show LGE or when it is there it is usually less dense, whereas bright LGE is frequent in AMI. ${ }^{17}$

Evidences in favor of TCM in this case were gender, age group, presence of a definite emotional and physical trigger, characteristic echocardiographic features, a higher InterTAK diagnostic score, absence of obstructive coronary lesions in angiogram and also not correlating with RWMA, disproportionately low cardiac enzymes, echocardiographic complete resolution of RWMA, and normalization of LV function within a month without any coronary

Table 1 The InterTAK diagnostic score at presentation

\begin{tabular}{|c|c|c|c|}
\hline S. No. & Clinical variables & $\begin{array}{l}\text { Maximum } \\
\text { points }\end{array}$ & Patient's points \\
\hline 1 & Female gender & 25 & 25 \\
\hline 2 & Emotional stress & 24 & 24 \\
\hline 3 & Physical stress & 13 & 13 \\
\hline 4 & $\begin{array}{l}\text { No ST-segment } \\
\text { depression }\end{array}$ & 12 & 12 \\
\hline 5 & $\begin{array}{l}\text { Acute, former, or } \\
\text { chronic psychiatric } \\
\text { disorder }\end{array}$ & 11 & 0 \\
\hline 6 & $\begin{array}{l}\text { Acute, former, or } \\
\text { chronic neurologi- } \\
\text { cal disorder }\end{array}$ & 9 & 0 \\
\hline \multirow[t]{2}{*}{7} & $\begin{array}{l}\text { Prolonged QTc time } \\
\text { (female > } 460 \mathrm{~ms} ; \\
\text { male > } 440 \mathrm{~ms} \text { ) }\end{array}$ & 6 & 0 \\
\hline & Total score & 100 & $\begin{array}{l}74(92.9 \% \\
\text { probability of } \\
\text { Takotsubo) }\end{array}$ \\
\hline
\end{tabular}


intervention. Evidences favoring myocardial embolization are the presence of underlying myxoma with high-risk features, temporal course of the disease, the hazy lesion in LCX ostium, recurrent chest pain with fresh ECG changes, and persistent bright LGE in CMR.

Even if embolization has occurred, the features satisfy the current diagnostic criteria for TCM. ${ }^{14}$ But it has to be understood that myocardial embolization and TCM are two distinct entities with different management strategies even though both can rarely coexist. ${ }^{16}$ Differentiating between these two is important because in case of embolization, early excision of the tumor could prevent recurrence and in turn decrease further morbidity and mortality. But in atrial myxoma associated with TCM, emergency surgery may not be mandatory. It would be prudent to wait until the LV function recovers. Several case reports raise the question of possible association between these two conditions ${ }^{2,3,45,9}$

Follow-up CMR confirmed this as a case of TCM occurring concurrently with AMI due to coronary embolization from atrial myxoma.

\section{Conclusion}

The following conclusions can be drawn from this case:

- Atrial myxoma is one of the rare nonatherosclerotic causes of acute myocardial infarction (AMI).

- A high index of suspicion is needed to diagnose myxoma in the setting of AMI as surgery is the only definitive treatment that improves prognosis. 2D echocardiography, preferably done before revascularization, helps to diagnose this condition and guide treatment properly.

- Takotsubo cardiomyopathy (TCM) can occur very rarely in the setting of atrial myxoma.

- In a patient with atrial myxoma presenting with features of TCM, differentiating it from myocardial embolization is crucial in guiding management decisions. CMR, both in acute setting and at follow-up, helps in making a definitive diagnosis. NT PRO BNP levels may be elevated in both the cases secondary to failure.

- Rarely, TCM can coexist with AMI. InterTAK diagnostic score can help in the diagnosis of TCM.

\section{Statement of Consent}

The authors confirm that written consent for submission and publication of this case report including image(s) and associated text has been obtained from the patient.

\section{Disclosure of Funding}

None.

\section{Conflict of Interest}

None declared.

\section{References}

1 Panos A, Kalangos A, Sztajzel J. Left atrial myxoma presenting with myocardial infarction. Case report and review of the literature. Int J Cardiol 1997;62(1):73-75

2 Shimada Y, Maeda K, Ogawa K, Oe H, Matsumura Y, Yoshiyama M. Three dimensional echocardiography of Takotsubo cardiomyopathy with atrial myxoma. BMJ Case Rep 2010;2010:2010

3 van der Hoeven NW, van Loon RB, Kamp O. 'A blessing in disguise': myxoma cordis and Takotsubo cardiomyopathy. Eur Heart J 2015;36(15):914

4 Seo SM, Park SK, Kim SJ, et al. Multiregional embolizations and Takotsubo cardiomyopathy associated with left atrial myxoma. Ann ThoracCardiovascSurg 2012;18(6):577-581

5 García-Delgado M, García-Huertas D, Navarrete-Sánchez I, Olivencia-Peña L, Garrido JM. Extracorporeal membrane oxygenation support for Takotsubo syndrome and long QT after cardiac surgery. Med Intensiva 2017;41(7):441-443

6 Napp LC, Ghadri JR, Bauersachs J, Templin C. Acute coronary syndrome or Takotsubo cardiomyopathy: the suspect may not always be the culprit. Int J Cardiol 2015;187:116-119

7 Lee S-J, Kim J-H, Na C-Y, Oh S-S. Eleven years' experience with Korean cardiac myxoma patients: focus on embolic complications. Cerebrovasc Dis 2012;33(5):471-479

8 Templin C, Ghadri JR, Diekmann J, et al. Clinical features and outcomes of Takotsubo (stress) cardiomyopathy. N Engl J Med 2015;373(10):929-938

9 Garagoli F, Arias A, Kotowicz V, Cagide A, Belziti C. Takotsubo cardiomyopathy with extracorporeal membrane oxygenation (ECMO) requirement after atrial myxoma surgery. Int J Cardiovasc Sci 2017;30:277-280

10 Hurst RT, Prasad A, Askew JW III, Sengupta PP, Tajik AJ. Takotsubo cardiomyopathy: a unique cardiomyopathy with variable ventricular morphology. JACC Cardiovasc Imaging 2010;3(6):641-649

11 Nascimento FO, Yang S, Larrauri-Reyes M, et al. Usefulness of the troponin-ejection fraction product to differentiate stress cardiomyopathy from ST-segment elevation myocardial infarction. Am J Cardiol 2014;113(3):429-433

12 Ghadri JR, Cammann VL, Jurisic $\mathrm{S}$, et al. InterTAK co-investigators. A novel clinical score (InterTAK Diagnostic Score) to differentiate Takotsubo syndrome from acute coronary syndrome: results from the International Takotsubo Registry. Eur J Heart Fail 2017;19(8):1036-1042

13 Carrillo A, Fiol M, García-Niebla J, Bayés de Luna A. Electrocardiographic differential diagnosis between Takotsubo syndrome and distal occlusion of LAD is not easy. J Am Coll Cardiol 2010;56(19):1610-1611, author reply 1611

14 Prasad A, Lerman A, Rihal CS. Apical ballooning syndrome (Takotsubo or stress cardiomyopathy): a mimic of acute myocardial infarction. Am Heart J 2008;155(3):408-417

15 Ghadri J-R, Wittstein IS, Prasad A, et al. International expert consensus document on Takotsubo syndrome (part II): diagnostic workup, outcome, and management. Eur Heart J 2018;39(22):2047-2062

16 Hussain MA, Cox AT, Bastiaenen R, Prasad A. Apical ballooning (Takotsubo) syndrome with concurrent ST-segment elevation myocardial infarction. BMJ Case Rep 2017;2017:2017

17 Abbas A, Sonnex E, Pereira RS, Coulden RA. Cardiac magnetic resonance assessment of takotsubo cardiomyopathy. ClinRadiol 2016;71(1):e110-e119 